\title{
The Colostomy Complications in Anorectal Malformation: A Retrospective Study
}

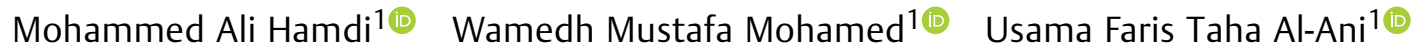 \\ 1 Department of Surgery, Abu Ghraib General Hospital, Baghdad \\ Alkarkh Health Directorate, Ministry of Health/Environment, \\ Baghdad, Iraq \\ J Coloproctol 2021;41(3):286-288. \\ Address for correspondence Usama Faris Taha Al-Ani, PhD, \\ Department of Surgery, Abu Ghraib General Hospital, Baghdad \\ Alkarkh Health Directorate, Ministry of Health/Environment, Baghdad \\ 10081, Iraq (e-mail: aqapiadil25@gmail.com).
}

\begin{abstract}
Keywords

- colostomy

- ano-rectal prolapse

- imperforate anus

- stoma

Background A colostomy is a surgical approach that creates an opening for the colon, or/and large intestine through the abdomen. Anorectal malformations are a group of abnormalities of the rectum and anus that are present at birth.

Objective To analyze the common complications of colostomy in anorectal formations. Methods This was a retrospective study conducted on 50 temporary colostomies performed in children at the Surgical Department of the Abu Ghraib General Hospital in the period from January 2018 to January 2020. Information was collected regarding the patients' age, sex, body weight, associated anomalies, colostomy types and sites, and the indications and complications of colostomies.

Results A total of $44(88 \%)$ cases were reported in the children's $1^{\text {st }}$ month of life. The ratio of male to female was $1: 1$. Pelvic colostomy was performed in 48 (96\%) patients, as $40(80 \%)$ children underwent a loop-type, and $8(16 \%)$ patients underwent doublebarrel colostomy. Transverse colostomy was performed on two patients. Prolapse occurred in $50 \%$ of the patients, and skin excoriations occurred in $22 \%$.

A total of $10 \%$ of the children developed sepsis. Bleeding was seen in $4 \%$ of the children after colostomy performance. Stenosis presented in $6 \%$ of the children, and this was corrected by repeated dilatation and re-fashioning. Obstruction of intestines was observed in one patient. The retraction developed in $6 \%$ of patients.

Conclusions Imperforate anus was the most common indication for stoma formation in the pediatric age group. Loop colostomy was the most common type used, and it had the highest rate of complications. Prolapses and skin excoriation were the most common complications found.
\end{abstract}

\section{Introduction}

A colostomy is a surgical procedure made in the large bowel to divert feces and flatus outside. ${ }^{1}$ There are different complications following the construction of colostomies, and the received

August 31, 2020

accepted after revision

January 15, 2021

published online

July 19, 2021
DOI https://doi.org/

10.1055/s-0041-1730259.

ISSN 2237-9363. overall morbidity has been as high as 42 to $75 \%{ }^{2,3}$ Complications may occur immediately after surgery, including: wound infection, abscess, peristomal fistula, stomal dysfunction, stomal retraction, bleeding, and small bowel obstruction, or there may be late complications, including:

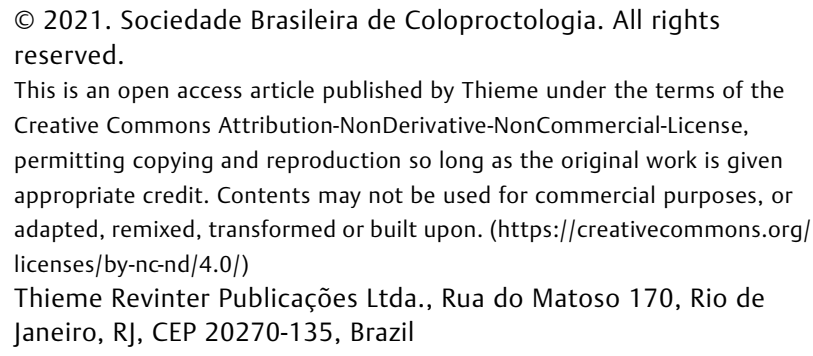

This is an open access article published by Thieme under the terms of the Creative Commons Attribution-NonDerivative-NonCommercial-License, permitting copying and reproduction so long as the original work is given appropriate credit. Contents may not be used for commercial purposes, or adapted, remixed, transformed or built upon. (https://creativecommons.org/ licenses/by-nc-nd/4.0/) Thieme Revinter Publicações Ltda., Rua do Matoso 170, Rio de Janeiro, RJ, CEP 20270-135, Brazil 
parastomal hernia, prolapse, stricture or stenosis, and poor shape and location of the stoma (skin excoriation). ${ }^{4-7}$

\section{Methods}

\section{Study Setting and Design}

A retrospective study was performed on 50 consecutive neonates, infants, and children who underwent surgery at the Surgical Department of the Abu Ghraib General Hospital in the period from January 2018 to January 2020.

\section{Participants}

The present study included 50 children with anorectal malformations. The data collected from the files of patients included: age, sex, weight, indications for colostomy, sites and types of colostomy, types of complications, and management. The stoma site and type were decided on according to the personal preference of the consultant surgeons.

\section{Surgical Interventions}

The operation was performed by both junior and consultant surgeons. Most of the colostomies performed for anorectal malformations were pelvic, and the preferred type was loop colostomy. From the 50 colostomies performed, 42 were emergency procedures, and only 8 were elective. Investigations were done for those patients, including complete blood count, plain X-ray for abdomen, invertogram, and ultrasound.

\section{Statistical Analysis}

All statistical procedures, analyses, and tests were applied using the IBM SPSS Statistics for Windows, Version 24.0 (IBM Corp. Armonk, NY, USA). The descriptive statistics were presented as mean, standard deviation, median, interquartile range (IQR), frequencies, and percentages. Continuous variables were tested for normal distribution. The Pearson correlation test, sample independent $t$-test, and Fisher exact test were used to compare two means of the normally distributed variable. The level of significance was set at 0.05 , below which the difference or correlation was considered to be significant.
Table 1 Stoma formation conditions and study variables

\begin{tabular}{|l|l|l|}
\hline \multicolumn{2}{|c|}{} & $\begin{array}{l}\text { Anorectal } \\
\text { malformations } \\
(\%)\end{array}$ \\
\hline $\begin{array}{l}\text { Age (weeks) } \\
4.65 \pm 2.38\end{array}$ & $0-4$ & $44(88)$ \\
\cline { 2 - 3 } & $5-52$ & $5(10)$ \\
\cline { 2 - 3 } & $>52$ & $1(2)$ \\
\hline \multirow{2}{*}{$\begin{array}{l}\text { Sex }(\text { M:F 1:1) } \\
\text { Pelvic colostomy }\end{array}$} & Male & $25(50)$ \\
\cline { 2 - 3 } & Female & $25(50)$ \\
\hline Transverse colostomy & Loop & $40(80)$ \\
\cline { 2 - 3 } & Double barrel & $8(16)$ \\
\cline { 2 - 3 } & Loop & $1(2)$ \\
\cline { 2 - 3 } & Double barrel & $1(2)$ \\
\hline
\end{tabular}

\section{Results}

A total of 44 (88\%) cases were observed in the children's $1^{\text {st }}$ month of life. A total of $10 \%$ of the children presented the condition in their $1^{\text {st }}$ year. And only $2 \%$ beyond the $1^{\text {st }}$ year of life. The ratio of male to female was $1: 1$.

Pelvic colostomy was performed in 48 (96\%) of patients, as 40 (80\%) children underwent the loop-type, and 8 (16\%) patients underwent the double-barrel colostomy. Transverse colostomy was performed on two patients, one with loop colostomy and the other with double barrel. Left gridiron incisions were used in all cases of pelvic colostomies to treat anorectal malformations.

Among the colostomy complications, prolapse occurred in $50 \%$, and skin excoriations occurred in $22 \%$ of the children.

A total of $10 \%$ of the children developed sepsis. Abscesses were reported in one patient who underwent pelvic doublebarrel colostomy. Bleeding was observed in $4 \%$ of the patients after colostomy performance. Stenosis presented in $6 \%$ of the children, and it was corrected by repeated dilatation and refashioning. Obstruction of the intestines was observed in one patient. The retraction developed in $6 \%$ of patients. ( - Tables 1 and 2)

Table 2 Complications of colostomy

\begin{tabular}{|c|c|c|c|c|c|c|c|c|c|}
\hline \multicolumn{2}{|l|}{ Colostomy } & Prolapse & Skin & Wound sepsis & Bleeding & Stenosis & Retraction & Intestinal & \multirow[t]{2}{*}{$P$-value } \\
\hline & & \multicolumn{7}{|l|}{ No (\%) } & \\
\hline \multirow[t]{2}{*}{ Pelvic } & Loop & $24(48)$ & $8(16)$ & $2(4)$ & $2(4)$ & $2(4)$ & $2(4)$ & 0 & \multirow[t]{2}{*}{0.05} \\
\hline & $\begin{array}{l}\text { Double } \\
\text { barrel }\end{array}$ & 0 & $3(6)$ & $3(6)$ & 0 & 0 & $1(2)$ & $1(2)$ & \\
\hline \multirow[t]{2}{*}{ Transverse } & Loop & $1(2)$ & 0 & 0 & 0 & 0 & 0 & 0 & \multirow[t]{2}{*}{0.2} \\
\hline & $\begin{array}{l}\text { Double } \\
\text { barrel }\end{array}$ & 0 & 0 & 0 & 0 & $1(2)$ & 0 & 0 & \\
\hline \multicolumn{2}{|l|}{ Total } & $25(50)$ & $11(22)$ & $5(10)$ & $2(4)$ & $3(6)$ & $3(6)$ & $1(2)$ & 50 \\
\hline
\end{tabular}




\section{Discussion}

Temporary colostomies are an important surgical step in the primary management of a variety of diseases in children. Most stoma formation was performed in the neonatal period because the patients with imperforate anus presented as an emergency, with intestinal obstruction immediately after birth. $5,7,8$

In our hospital, most surgeons prefer to do pelvic colostomies, as the loop-type is used in $80 \%$ of the cases and the double barrel in $16 \%$, because most cases do not required laparotomy. There are lower rates of complications, and it is easy to do distal colostogram to delineate the level of rectum end. ${ }^{6,9}$

The most common complication observed was colostomy prolapse, and it occurred most frequently in right loop pelvic colostomy. The second most common complication was skin excoriation, and this high incidence was due to poor compliance of patients with colostomy equipment, especially patients from rural areas, where there is shortage in the supply of colostomy equipment in hospitals and equipment is expensive outside the hospital. Wound sepsis includes local wound infection, peristomal abscess, and fistula and this complication most likely occurred due to imperfect nursing care only. The reasons for stenosis was due to a small opening that was creating for colostomy and ischemia of margins of stoma. ${ }^{10}$ Patients treated by dilatation under general anesthesia and some patients required revision.

In general, all children developed different complications directly related to stoma formation that was high in comparison to other studies. ${ }^{9-12}$ The causes for this high rate of complications are probably related to poor and bad care for a colostomy.

\section{Conclusions}

Anorectal malformation was the most common indications for temporary colostomy in children. Right loop colostomy had the highest rate of complications, whereas the doublebarrel type carried fewer complications. We recommend the creation of colostomy by well-trained surgeons. A doublebarrel colostomy is the approach of choice for imperforate anus because of its complete fecal diversion and low inci- dence of complications. Anal surgical intervention should be done as early as possible to reduce the length of time that patient needs to have a stoma.

\section{Conflict of Interests}

The authors declare that there is no conflict of interests.

\section{Acknowledgment}

All authors thank Dr. Mohammad F Al-Dahan from Creffiel Medical Centre (London, UK), for his helping.

\section{References}

1 Williams NS, O'connell PR, McCasksie A. (2014). In:Rains HAJ, Mann CV, (editors). Bailey and Love's: Short practice of surgery. 27th edition. CRC Press, Taylor and Francis GroupLondon, UK2014

2 al-Salem AH, Grant C, Khawaja S. Colostomy complications in infants and children. Int Surg 1992;77(03):164-166

3 Stothert JC Jr, Brubacher L, Simonowitz DA. Complications of emergency stoma formation. Arch Surg 1982;117(03):307-309

4 dos Santos OJ, Filho ENS, Filho AKDB, et al. Children and adolescents ostomized in a reference hospital: Epidemiological profile. J Coloproctol (Rio J) 2016;36(02):75-79

5 Salgado-Cruz LE, Espin-Basany E, Chapa-Lobo AF, Rangel-Ríos HA, Garza-Maldonado AG, de Elguea-Lizárraga JO. Double barreled wet colostomy: Case report and description of the surgical technique. J Coloproctol (Rio J) 2020;40(04):390-393

6 Alwi F. Setiawan, Asrizal. Quality of life of persons with permanent colostomy: a phenomenological study. J Coloproctol (Rio J) 2018;38(04):295-301

7 de Campos K, Bot LHB, Petroianu A, Rebelo PA, de Souza AAS, Panhoca I. The impact of colostomy on the patient's life. J Coloproctol (Rio J) 2017;37(03):205-210

8 de Lima JA, Muniz KC, Salomé GM, Ferreira LM. Association of sociodemographic and clinical factors with self-image, self-esteem and locus of health control in patients with an intestinal stoma. J Coloproctol (Rio J) 2018;38(01):56-64

9 de Sousa MJ, Andrade SSC, de Brito KKG, Matos SDO, Coêlho HFC, Oliveira SHS. Sociodemographic and clinical features and quality of life in stomized patients. J Coloproctol (Rio J) 2016;36(01): 27-33

10 Chandramouli B, Srinivasan K, Jagdish S, Ananthakrishnan N. Morbidity and mortality of colostomy and its closure in children. J Pediatr Surg 2004;39(04):596-599

11 Sheikh MA, Akhtar J, Ahmed S. Complications / problems of colostomy in infants and children. J Coll Physicians Surg Pak 2006;16(08):509-513

12 Nour S, Beck J, Stringer MD. Colostomy complications in infants and children. Ann R Coll Surg Engl 1996;78(06):526-530 